\begin{tabular}{lcl} 
Bentham OPEN & The Open PSychology Journal \\
CrossMark & Content list available at: www.benthamopen.com/TOPSYJ/ \\
DOI: $10.2174 / 1874350101710010118$ & $\substack{\text { The } \\
\text { Open Psychology } \\
\text { lournal }}$ \\
\hline
\end{tabular}

RESEARCH ARTICLE

\title{
Validation of a Vibrotactile Stimulation System Using the Wii Remote for Studies of Tactile Sensitivity
}

\author{
Eri Sugimoto and Hitoshi Sasaki \\ Vocational College of Osaka Judo Therapist Association, Osaka, 550-0004, Japan
}

Received: May 08, 2017

Revised: June 04, 2017

Accepted: July 08, 2017

\begin{abstract}
:
Background:

Vibrotactile stimuli are widely used to study the functional characteristics of the haptic sense. Although many vibrotactile stimulators are commercially available, most are expensive.
\end{abstract}

\section{Objective:}

We developed a low-cost vibrotactile stimulation system using a Nintendo Wii Remote and a personal computer. In the present study, we examined the validity and accuracy of this vibrotactile stimulation system.

\section{Method:}

In the first experiment, we measured the linearity of vibration amplitude and changes in peak vibration frequency generated by the Wii Remote as a function of activation intensity. In the second experiment, the effect of vibrotactile stimuli applied to the dorsal surface of hand on two-point discrimination threshold at the index finger was examined in twelve participants.

\section{Results:}

The peak vibration frequency was about $150 \mathrm{~Hz}$ irrespective of vibration intensity, which would effectively activate fast adapting type II (FAII) cutaneous mechanical receptors. The two-point discrimination threshold measured at the third pad of the index finger decreased significantly when a near-threshold vibrotactile stimulus was applied to the dorsal hand, a response termed stochastic resonance (SR). These SR results are consistent with findings in the other sensory systems, such as auditory, visual, and somatosensory systems.

\section{Conclusion:}

This newly developed stimulation system produces controllable vibrotactile stimuli useful for study of the haptic sense.

Keywords: Vibrotactile noise, Touch sense, Tactile sensation, Cutaneous mechanical receptors, Two-point discrimination threshold, Somatosensory, Stochastic resonance, Humans.

\section{INTRODUCTION}

Vibrotactile stimulation is widely applied in the study of haptic sensory function [1 - 3] as well as for tactile sensors and displays $[4,5]$. Several systems have been developed to generate vibrotactile stimuli, including a motor for repeated touch stimulation [6,7], a moving magnet linear actuator [8], a voice coil actuator [9], and a piezoelectric actuator [10 - 12]. In addition, several mechanical stimulators are commercially available. However, most are expensive or a frequency characteristic changes with amplitude. To mitigate this problem, we have developed a low-cost vibrotactile

\footnotetext{
* Address correspondence to this author at the Vocation College of Osaka Judo Therapist Association 3-10-3 Utsubohommachi, Nishi-ku, Osaka 550-0004, Japan, Tel: +81 66444 4171; E-mail: H.Sasaki@Physiol.com
} 
stimulating system using the Nintendo Wii Remote and a personal computer (PC). This wireless device is the man-machine interface for Nintendo Wii and Wii U consoles and is equipped with a small oscillator as well as an infrared sensor and multiple acceleration sensors. The Wii Remote uses Bluetooth for console communication. In our system, we control the Wii Remote oscillator by PC software via Bluetooth. Here we examined the accuracy and experimental utility of vibrotactile stimulation generated by the Wii Remote.

\section{EXPERIMENT-1}

In the first experiment, we analyzed the linearity and reproducibility of amplitude and the changes in peak vibration frequency generated by the Wii Remote as a function of activation intensity.

\section{METHODS}

\subsection{Apparatus}

In order to stabilize the source currents for the Wii Remote (RVL-003, Nintendo), we used DC currents from a USB port (USB feed adopter, CY-WIURUSAD-WH, Cyber) rather than the internal batteries $(1.5 \mathrm{~V} \times 2)$. We used a PC running Windows XP and an open-source program (Wiibrator02.exe; [http:/www.kako.com/ neta/2006-019/ wii_brator2a.zip] 2016/12/26) to control the Wii Remote via a Bluetooth USB adapter (BT-Mixro3E2X, PCI). The software generates four intensities of vibration as selected by the $[+]$ and $[-]$ buttons, and controls stimulus "on"/"off" by the [A] button. The selected intensity is indicated by LEDs on the Wii Remote. However, in preliminary studies, we found that the time course of the vibration differed among intensity levels. In particular, an irregular beat oscillation was observed at some intensity. Thus, we chose the 4th intensity (maximum) for subsequent studies because the beat is the smallest, and modified output intensity by cushioning sheets as described below.

\subsection{Recording of Vibration}

The frequency distribution and amplitude of the vibration were measured using an accelerometer (GH313A, GA-245SO, Keyence). The Wii Remote was placed on a small table ( $45 \mathrm{~cm}$ wide, $65 \mathrm{~cm}$ long, and $2 \mathrm{~cm}$ thick) and the sensor of the accelerometer was affixed on the tabletop $5 \mathrm{~cm}$ from the Wii Remote using double-faced adhesive tape to capture traveling vibrations. This accelerometer position was selected as the midpoint between the stimulator (Wii Remote) and the participant's dorsal hand in experiment 2 (10 cm away as described below). The output of the accelerometer was input to an oscilloscope and an A/D converter (MacLab, A/D Instruments) with a sampling rate of 1 $\mathrm{kHz}$. The digitized waveforms were then stored on the hard disk of a PC (Macintosh, Apple). Power spectrograms of the recorded waves were produced by Fast Fourier Transform (FFT) with a sampling number of 1024 (Chart v.3.5.6, A/D Instruments).

\subsection{Procedures}

As described above, the vibration intensity setting of the software (activation intensity) was fixed at the level producing the smallest beat. We therefore changed the intensity of vibrational output using a variable number of cushioning sheets between the vibrator (Wii Remote) and the table. Specifically, intensity was reduced by increasing the number of sheets from 1 to 4 . Thus, this vibrotactile system was designed to apply the stimulus simultaneously to a relatively wide area of the hand when placed on the tabletop $10 \mathrm{~cm}$ from the Wii device.

\section{RESULTS}

Changes in vibration amplitude as a function of output intensity are shown in Fig. (1). The vibration output intensity was changed from level 1 (S1, lowest) to level 5 (S5, highest) by decreasing the number of cushioning sheets between the Wii Remote and tabletop from four to none, respectively. The amplitude of vibration was measured by the accelerometer output voltage. As expected, vibration amplitude increased progressively with output intensity level (Fig. 1), and the relationship was nearly linear.

Fig. (2) shows the frequency power spectra from 0 to $500 \mathrm{~Hz}$ for all six vibration intensities (S0-S5). The spectral pattern was similar at each non-zero intensity (S1-S5), with peak frequency at about $150 \mathrm{~Hz}$. This peak disappeared at S0 (no vibration). 


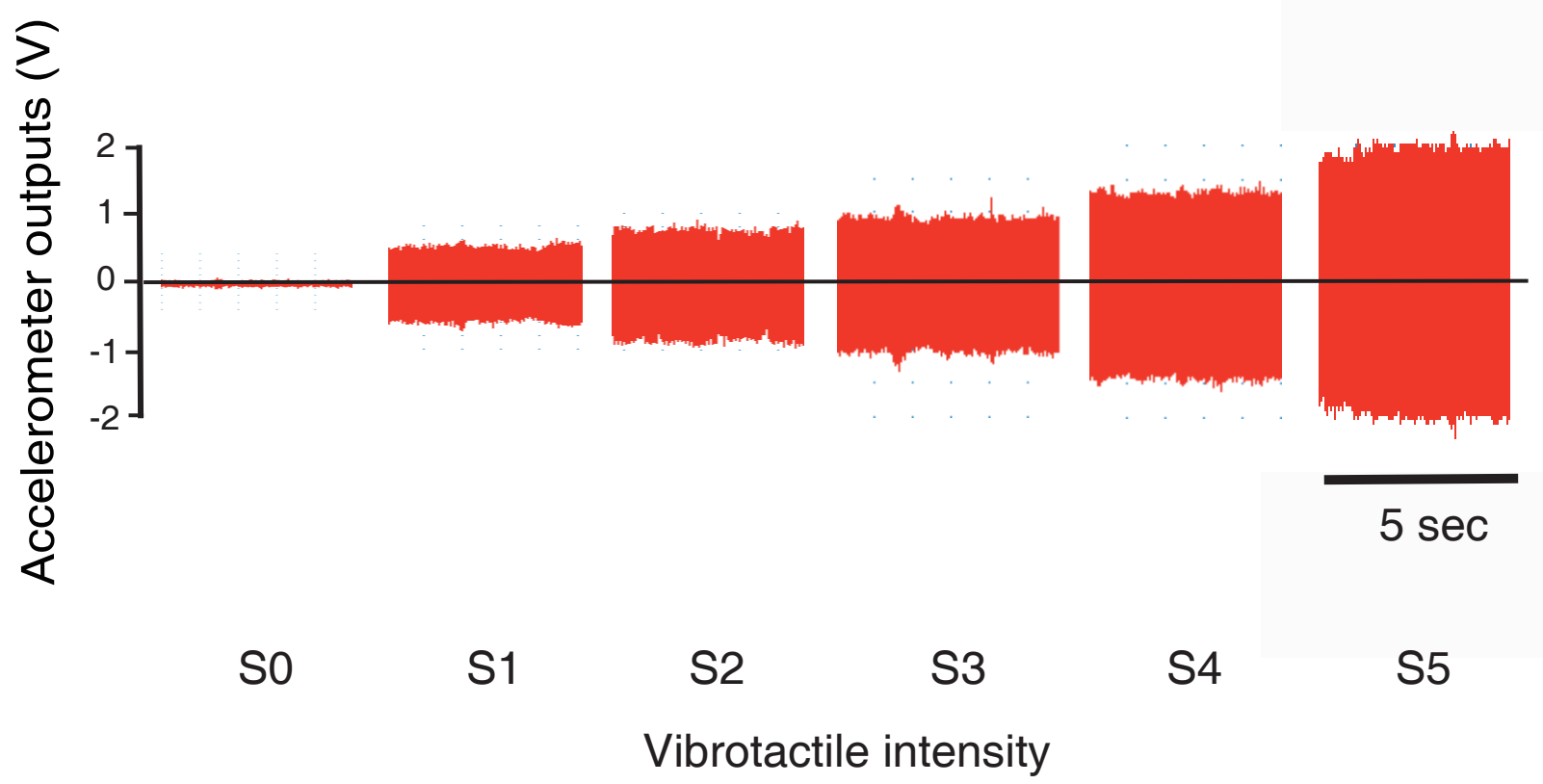

Fig. (1). Change in accelerometer mean output voltage as a function of vibration intensity. Vibration intensity was manipulated by changing the number of cushioning sheet between the surface (tabletop) and the vibration source (Wii Remote). Control (S0) means no vibration stimulus.

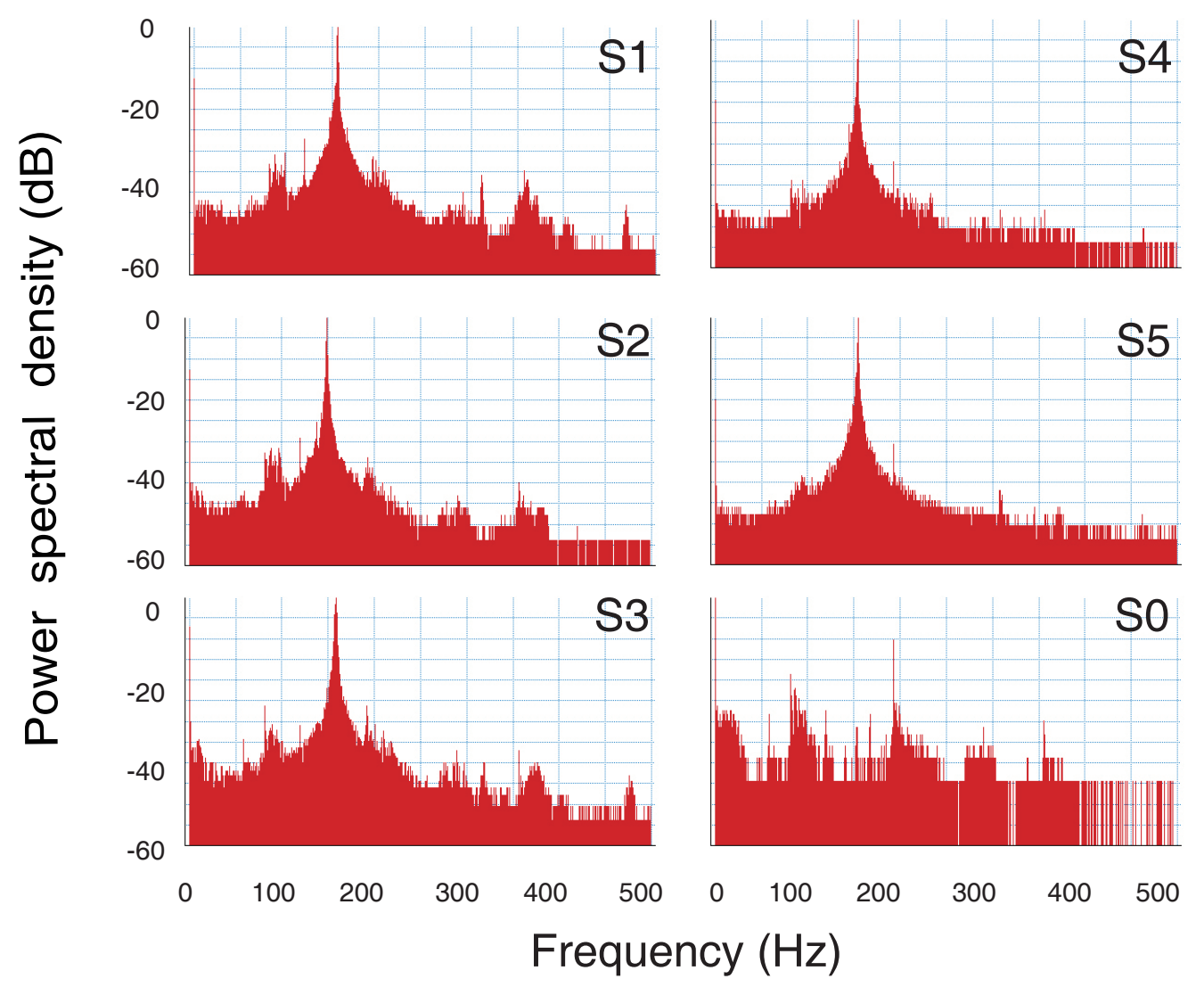

Fig. (2). Frequency power spectra computed by Fast Fourier Transform (FFT) over five seconds at different vibration intensities. Insert (top right) in each panel indicates the intensity of vibration (S1-S5). The peak frequency was around $150 \mathrm{~Hz}$ for all intensities except for the control (S0). 


\subsection{Experiment-2}

In the second experiment, the validity and utility of the Wii Remote were tested in a psychophysical study examining modification of two-point discrimination threshold by vibrotactile stimulation.

Noise is generally thought to hinder signal detection. However, normally undetectable signals can be perceived by addition of weak noise to the signals in a non-linear system, a phenomenon called stochastic resonance (SR) [13]. Improved signal detection by weak noise input has been studied not only in the field of physical events but also in biological systems, including human sensory systems [14 - 16]. In the human somatosensory system, touch sensation of the hand can be enhanced by weak vibrotactile noise $[6,12,17]$. Collins and colleagues found that detection of a touch stimulus to the hand improved when vibration noise was added to the touch stimulus. In addition, they demonstrated that impaired sensitivity to tactile stimuli to the foot can be reversed by localized low-level electrical noise in patients suffering from peripheral nerve diseases [6, 7]. Kurita et al. [12] found that two-point discrimination threshold at the tip of the index finger was improved significantly when a weak noise stimulus was applied simultaneously to the side of the index finger. Collectively, these studies indicate that tactile sense can be improved by near-threshold noise if applied close to the site of the test stimulus.

In SR, addition of a weak noise around its detection threshold improves subliminal signal detection, while more intense noise either has no effect or impairs detection. Thus, the detection threshold will show a U-shaped function with noise intensity [18 - 20]. In the present experiment, we examined the effect of remote vibration applied to the dorsal surface of hand on the two-point threshold measured at the third pad of the index finger.

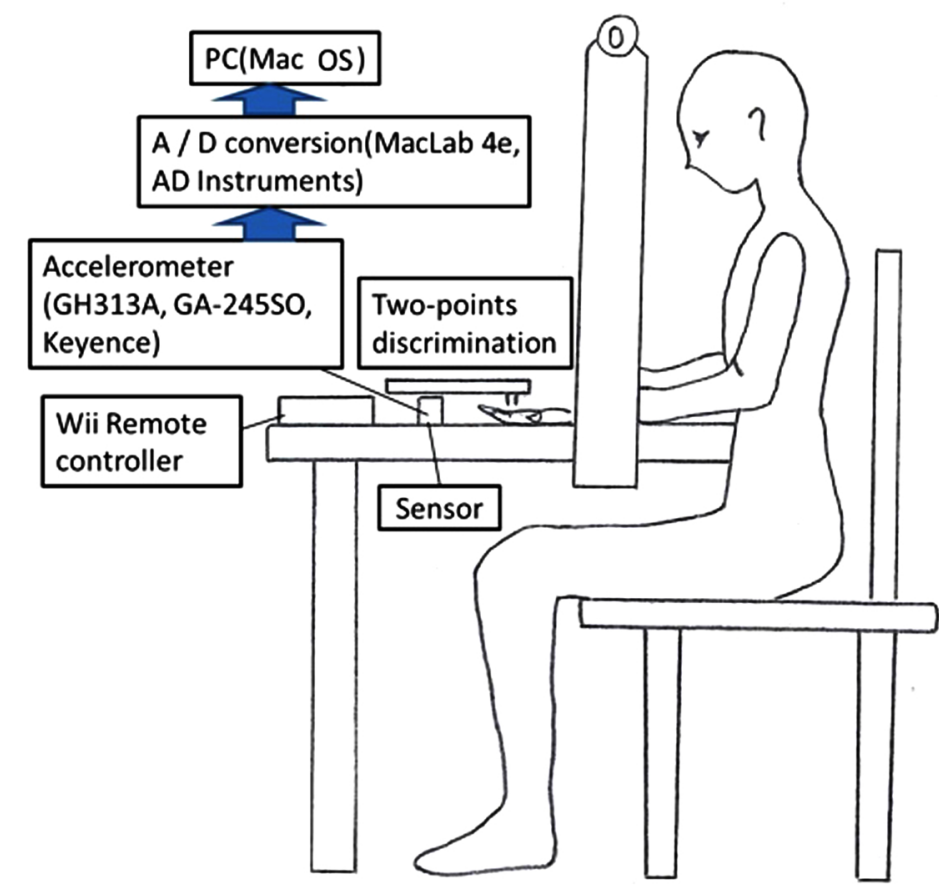

Fig. (3). Schematic drawing of experimental set-up. Participants were seated at a table on which the Wii remote controller was placed, with their left hand placed palm upwards on the table. The vibrotactile stimulation was applied widely to the dorsal surface of the hand.

\section{METHODS}

\subsection{Participants}

Twelve male vocational college students participated in this experiment (mean age $\pm \mathrm{SD}, 26.4 \pm 12.11$ years). All participants gave their informed consent and all experimental treatments conformed to the Declaration of Helsinki (1964). 


\subsection{Apparatus}

Two-point discrimination threshold was measured using an electric digital caliper (cw-80216m, Freedom) attached to two metal shafts $0.2-\mathrm{mm}$ in diameter. Vibrotactile noise was generated using the Wii Remote described in Experiment 1.

\subsection{Procedures}

Participants were seated at a table on which the vibrotactile stimulator was placed, with their left hand (nondominant hand) placed palm upwards on the table. The experimental room was maintained at $25.0^{\circ} \mathrm{C} \pm 0.85^{\circ} \mathrm{C}(\mathrm{mean} \pm$ $\mathrm{SD}$ ). The parts of the fingers distal to the metacarpophalangeal (MCP) joints were flexed lightly (upward) so that the vibrotactile stimulus was applied only to the back of the hand. The distance between the Wii Remote and hand was about $10 \mathrm{~cm}$, and the accelerometer was set at the mid-point. The visual field was partially restricted by a partition so that subjects could not see their hands (Fig. 3).

Two-point discrimination threshold was measured at the $3 \mathrm{rd}$ pad of the index finger (the palm-side skin surface at the proximal phalanx of the index finger) by the psychophysical constant method using six tip separation distances (1.5, 2.0, 2.5, 3.0, 3.5, and 4.0mm). In order to examine the effect of vibration noise on two-point discrimination, one of five noise intensities (S1-S5) or a no-noise condition (S0; control) was presented simultaneously with the tactile test stimuli.

The detection threshold of vibrotactile noise was pre-determined as S3 for each participant using the method of limits. Then, the other intensities were produced by decreasing (S4, S5) or increasing the number of cushioning sheet $(\mathrm{S} 1, \mathrm{~S} 2)$ in the same way in all participants.

Two-point discrimination threshold was measured during 2-s stimulus periods separated by 3-s response periods. A full session consisted of 60 measurement trials, and a total of 6 sessions were performed with an inter-session interval of 30s. The noise intensity was fixed during each session and was presented continuously throughout the session. The presentation orders of tip separation distance and noise intensity were quasi-random in each participant. A complete experiment lasted about $45 \mathrm{~min}$.

\subsection{Data Analysis}

At each noise intensity level, tip separation distance for the $50 \%$ correct response rate (threshold) was calculated using the least-squares method. The obtained two-point threshold was normalized to the two-point threshold in the control condition (S0) to establish a uniform baseline across participants. From the normalized data, the median ( \pm quartile) was calculated at each noise intensity level. A priori analysis using the sign test (one-sided) after Bonferroni correction was performed to test the effect of vibrotactile noise on two-point discrimination because the effect would be expected only for noise intensity around its detection threshold and because the two-point threshold could only decrease if the noise were effective.

\section{RESULTS}

The mean $( \pm \mathrm{SE})$ noise threshold for all twelve participants was $1.4 \pm 0.16 \mathrm{~V}$. The mean amplitude of vibration increased with intensity as adjusted by the number of cushioning sheets. The amplitude of vibration relative to threshold intensity at $\mathrm{S} 3$ was 0.6 at S1, 0.7 at S2, 1.5 at S4, and 1.6 at S5 (Fig. 4).

Two-point discrimination threshold in the control condition (S0) was $2.60 \pm 0.26 \mathrm{~mm}$ (mean $\pm \mathrm{SE}$ ) at the $3 \mathrm{rd}$ pad of the index finger. Addition of a weak noise from the Wii Remote improved two-point discrimination, indicating successful induction of SR. Fig. (5) shows the change in two-point threshold with noise intensity. The two-point threshold decreased (improved) when a weak noise (S4) around its detection threshold (S3) was applied (0.90 \pm 0.22 at $\mathrm{S} 4$ vs. $0.94 \pm 0.22$ at S3). Statistical analysis revealed a significant decrease in two-point threshold at S4 compared to control ( $\mathrm{p}=0.0215 / 2, \mathrm{r}=0.70)$, while more intense noise (S5) increased two-point threshold (i.e., reduced two-point discrimination). Less intense noise (S1 and S2) had no effect. Thus, the change in two-point discrimination exhibited a U-shaped relation with noise intensity, which is characteristic of SR.

\section{DISCUSSION}

\subsection{Features of the Vibrotactile Stimulation System}

The vibrotactile stimulation system developed here, has two remarkable features. One is stability of frequencies 
regardless of changes in amplitudes. As shown in Fig. (2), frequencies remained unchanged independent of changes in amplitudes. This is especially important in experiments, in which an independent variable is intensity of vibration. Another feature is that the present stimulator can provide vibration stimulus to a relatively wide area of the skin simultaneously, such as a whole area of the dorsal hand. Thus, we can examine the effect of remote vibration applied to a wide area of skin (not to a restricted area near the recording site) on the two-point threshold. The remote stimulation technique is especially important for the clinical use of SR to improve the two-point threshold, because sometimes actuators cannot be placed near the impaired site of patients.

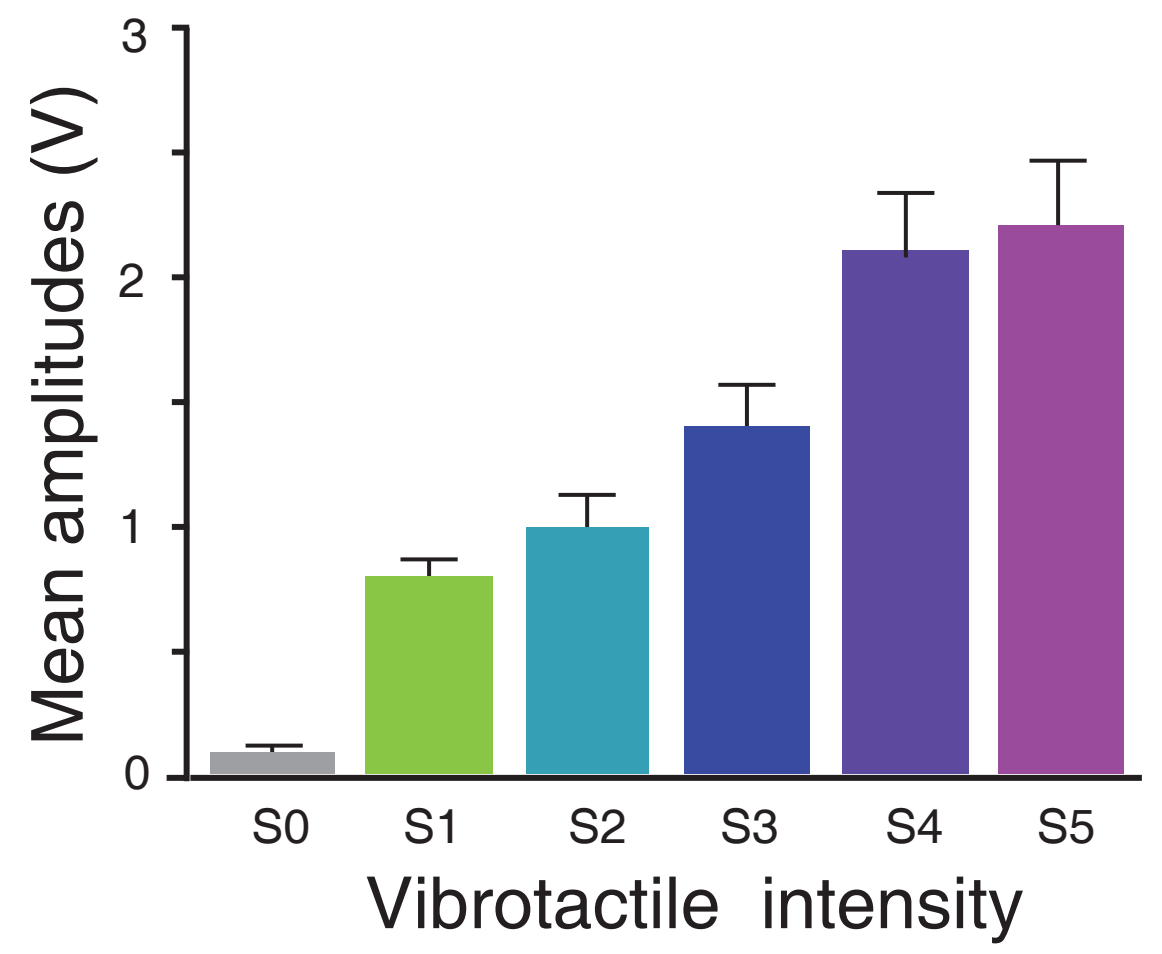

Fig. (4). Mean peak-to-peak amplitude $( \pm S E M)$ of the accelerometer output with changing vibration intensity. The mean threshold intensity of vibration in twelve participants was S3 $(1.4 \pm 0.16 \mathrm{~V})$. S0 represents no vibration stimulus. The amplitude increased monotonically with greater vibration intensity.

\subsection{Mechanoreceptors Responsible for Two-point Discrimination}

Cutaneous mechanical units in glabrous skin have been classified into four groups, fast adapting types I and II (FAI and FAII) and slowly adapting types I and II (SAI and SAII) that differ in receptive field size and stimulus response patterns $[21,22]$. The receptive field sizes of FAI and SAI are small $\left(12.6\right.$ and $11.0 \mathrm{~mm}^{2}$, respectively), while the receptive field sizes of FAII and SAII are relatively large (101.0 and 59.0 $\mathrm{mm}^{2}$, respectively). In addition, the receptive field border is clear for FAI and SAI but indistinct for FAII and SAII [23]. Spatial resolution is about $0.6 \mathrm{~mm}^{-1}$ at the tip of the index finger, $0.25 \mathrm{~mm}^{-1}$ at the third pad of the index finger, and $0.1 \mathrm{~mm}^{-1}$ at the thenar eminence, acuities that parallel respective FAI and SAI receptor densities at each site, specifically 140 and $70 \mathrm{units} / \mathrm{cm}^{2}$ at the tip, 40 and 35 units $/ \mathrm{cm}^{2}$ at the third pad, and 30 and 5 units $/ \mathrm{cm}^{2}$ at the thenar eminence. In contrast, FAII and SAII receptor densities are constant across these sites. Therefore, FAI and SAI appear to be the mechanical units responsible for two-point discrimination by the index finger.

\subsection{Frequency response Characteristics of the Cutaneous Mechanoreceptors}

At least three cutaneous mechanical unit types respond to vibrational stimuli applied to the glabrous skin surface, SAI, FAI, and FAII. Of these, the threshold level is lowest for FAII [22]. In addition, the optimal frequency range is low for SAI and SAII, intermediate for FAI, and highest for FAII, with optimal frequency for FAII ranging from 100 to $300 \mathrm{~Hz}$ [22]. As the peak frequency of the vibrotactile stimulation system developed here was about $150 \mathrm{~Hz}$, it is likely that FAII was predominantly responsible for the vibrotactile response. 


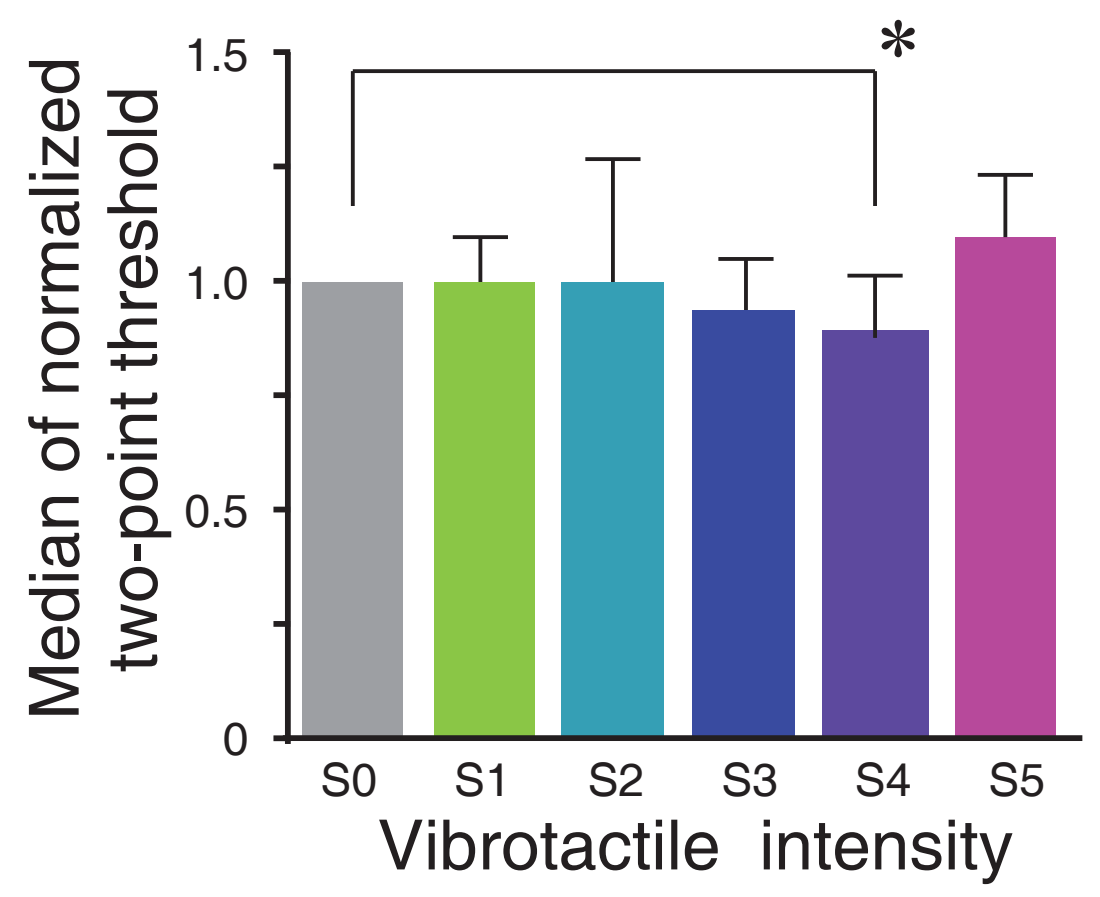

Fig. (5). Median ( \pm quartile) two-point discrimination threshold as a function of vibrotactile noise intensity normalized to S0 (nonoise). The two-point threshold was measured at the third pad of the non-dominant index finger, while the vibrotactile noise was applied to the dorsal part of the same hand. The median score decreased significantly at intensity level S4 compared to no noise $\left({ }^{*} \mathrm{p}<\right.$ $0.05 / 3)$. S3 was the threshold intensity for all 12 participants.

\subsection{Subliminal Summation of Signal and Noise}

Subliminal summation of signal and noise has been proposed to explain SR [24 - 27]. Noise is irregular in nature, so the sum of signal and noise is also irregular. Therefore, subliminal summation will exceed the detection threshold level in a stochastic manner when the noise intensity is weak. If noise intensity is too strong, however, the sum will always exceed the threshold. Conversely, if noise intensity is too weak, the sum will never exceed the threshold. Thus, an optimal (near-threshold) intensity must be present for SR to occur.

Little is known about the site of summation. Both external and internal SR has been demonstrated [28]. For internal SR, at least two sites are possible, receptors and the central nervous system (CNS) neurons [29]. In the present study, summation at the receptor level can be excluded because the mechanoreceptors responsible for signal and noise seems to be different. In addition, vibration amplitude decreases rapidly as it travels on the skin, with approximately $99 \%$ of the power lost over the first $6 \mathrm{~cm}$ [30]. It thus appears more likely that the summation occurs at the cortical neuron level.

\section{CONCLUSION}

We have developed a new vibrotactile stimulation system consisting of a Wii Remote under PC control. In the first experiment, we examined the linearity and reproducibility of vibration amplitude and the stability of the frequency spectrum with stimulator (Wii Remote) activation intensity. Peak frequency was about $150 \mathrm{~Hz}$ irrespective of intensity, suitable for FAII activation. This system is low-cost and useful for experiments using vibration stimuli, especially experiments using both subthreshold and suprathreshold stimuli.

In the second experiment, we evaluated the utility of this vibrotactile stimulation system by examining its effect on tactile sensitivity. Two-point discrimination threshold measured at the third pad of the index finger was improved when a weak vibrotactile stimulus (noise) was applied to the back of the same hand, while more intense and less intense vibrotactile noise did not improve tactile sensitivity. These results are consistent with the known behavior of SR in other sensory modalities and further suggest that remote application of vibrotactile noise can increase skin mechanical sensitivity at a distant site via SR. These results confirmed the accuracy and validity of our newly developed vibrotactile stimulation system. 


\section{ETHICS APPROVAL AND CONSENT TO PARTICIPATE}

Not applicable.

\section{HUMAN AND ANIMAL RIGHTS}

No Animals/Humans were used for studies that are base of this research.

\section{CONSENT FOR PUBLICATION}

Not applicable.

\section{CONFLICT OF INTEREST}

The authors declare no conflict of interest, financial or otherwise.

\section{ACKNOWLEDGEMENTS}

Decleared none.

\section{REFRENCES}

[1] Verrillo RT, Fraioli AJ, Smith RL. Sensation magnitude of vibrotactile stimuli. Percept Psychophys 1969; 6: $366-72$. [http://dx.doi.org/10.3758/BF03212793]

[2] Burton H, Sinclair RJ, McLaren DG. Cortical activity to vibrotactile stimulation: an fMRI study in blind and sighted individuals. Hum Brain Mapp 2004; 23(4): 210-28. [http://dx.doi.org/10.1002/hbm.20064] [PMID: 15449356]

[3] Stach T, Graham T. Exploring haptic feedback in exergames. Human-Computer Interaction-INTERACT 2011; 2: 18-35 [http://dx.doi.org/10.1007/978-3-642-23771-3_2]

[4] Kawasaki H, Komatsu T, Uchiyama K. Dexterous anthropomorphic robot hand with distributed tactile sensor: Gifu hand II. IEEE/ASME Trans Mechatron 2002; 7: 296-303. [http://dx.doi.org/10.1109/TMECH.2002.802720]

[5] Kaczmarek KA, Webster JG, Bach-y-Rita P, Tompkins WJ. Electrotactile and vibrotactile displays for sensory substitution systems. IEEE Trans Biomed Eng 1991; 38(1): 1-16. [http://dx.doi.org/10.1109/10.68204] [PMID: 2026426]

[6] Collins JJ, Imhoff TT, Grigg P. Noise-enhanced tactile sensation. Nature 1996; 383(6603): 770. [http://dx.doi.org/10.1038/383770a0]

[7] Dhruv NT, Niemi JB, Harry JD, Lipsitz LA, Collins JJ. Enhancing tactile sensation in older adults with electrical noise stimulation. Neuroreport 2002; 13(5): 597-600. [http://dx.doi.org/10.1097/00001756-200204160-00012] [PMID: 11973453]

[8] Enders LR, Hur P, Johnson MJ, Seo NJ. Remote vibrotactile noise improves light touch sensation in stroke survivors' fingertips via stochastic resonance. J Neuroeng Rehabil 2013; 10(1): 1.

[9] Holden JK, Nguyen RH, Francisco EM, Zhang Z, Dennis RG, Tommerdahl M. A novel device for the study of somatosensory information processing. J Neurosci Methods 2012; 204(2): 215-20. [http://dx.doi.org/10.1016/j.jneumeth.2011.11.007] [PMID: 22155443]

[10] Lim SC, Kyung KU, Kwon DS. Effect of frequency difference on sensitivity of beats perception. Exp Brain Res 2012; 216(1): 11-9. [http://dx.doi.org/10.1007/s00221-011-2864-z] [PMID: 22028052]

[11] Beceren K, Ohka M, Jin T, Miyaoka T, Yussof H. Human Tactile Stochastic Resonance Affected by Stimulus Direction. Int J Adv Robot Syst $2013 ; 10$.

[12] Kurita Y, Shinohara M, Ueda J. Wearable sensorimotor enhancer for fingertip based on stochastic resonance. IEEE Trans Hum Mach Syst 2013; 43: 333-7. [http://dx.doi.org/10.1109/TSMC.2013.2242886]

[13] Wiesenfeld K, Moss F. Stochastic resonance and the benefits of noise: from ice ages to crayfish and SQUIDs. Nature 1995; 373(6509): 33-6. [http://dx.doi.org/10.1038/373033a0] [PMID: 7800036]

[14] Gammaitoni L, Hanggi P, Jung P, Marchesoni F. Stochastic resonance. Rev Mod Phys 1998; 70: $223-87$. [http://dx.doi.org/10.1103/RevModPhys.70.223]

[15] Moss F, Ward LM, Sannita WG. Stochastic resonance and sensory information processing: a tutorial and review of application. Clin Neurophysiol 2004; 115(2): 267-81. [http://dx.doi.org/10.1016/j.clinph.2003.09.014] [PMID: 14744566]

[16] McDonnell MD, Abbott D. What is stochastic resonance? Definitions, misconceptions, debates, and its relevance to biology. PLOS Comput 
Biol 2009; 5(5): e1000348.

[http://dx.doi.org/10.1371/journal.pcbi.1000348] [PMID: 19562010]

[17] Seo NJ, Lakshminarayanan K, Bonilha L, Lauer AW, Schmit BD. Effect of imperceptible vibratory noise applied to wrist skin on fingertip touch evoked potentials - an EEG study. Physiol Rep 2015; 3(11): e12624. [http://dx.doi.org/10.14814/phy2.12624] [PMID: 26603457]

[18] Bahar S, Moss F. Stochastic resonance and synchronization in the crayfish caudal photoreceptor. Math Biosci $2004 ; 188: 81-97$. [http://dx.doi.org/10.1016/j.mbs.2003.09.004] [PMID: 14766095]

[19] Sasaki H, Todorokihara M, Ishida T, Miyachi J, Kitamura T, Aoki R. Effect of noise on the contrast detection threshold in visual perception. Neurosci Lett 2006; 408(2): 94-7. [http://dx.doi.org/10.1016/j.neulet.2006.08.054] [PMID: 16996210]

[20] Sasaki H, Sakane S, Ishida T, Todorokihara M, Kitamura T, Aoki R. Subthreshold noise facilitates the detection and discrimination of visual signals. Neurosci Lett 2008; 436(2): 255-8.

[http://dx.doi.org/10.1016/j.neulet.2008.03.036] [PMID: 18400398]

[21] Vallbo ÅB, Johansson RS. Properties of cutaneous mechanoreceptors in the human hand related to touch sensation. Hum Neurobiol 1984; 3(1): 3-14.

[PMID: 6330008]

[22] Bolanowski SJ Jr, Gescheider GA, Verrillo RT, Checkosky CM. Four channels mediate the mechanical aspects of touch. J Acoust Soc Am 1988; 84(5): 1680-94. [http://dx.doi.org/10.1121/1.397184] [PMID: 3209773]

[23] Johansson RS, Vallbo ÅB. Tactile sensory coding in the glabrous skin of the human hand. Trends Neurosci 1983; 6: 27-32. [http://dx.doi.org/10.1016/0166-2236(83)90011-5]

[24] Gingle Z, Kiss LB, Moss F. Non-dynamical stochastic resonance: theory and experiments with white and arbitrarily coloured noise. Europhys Lett 1995; 29: 191-6.

[http://dx.doi.org/10.1209/0295-5075/29/3/001]

[25] Simonotto E, Riani M, Seife C, Roberts M, Twitty J, Moss F. Visual perception of stochastic resonance. Phys Rev Lett 1997; 78: 1186-9. [http://dx.doi.org/10.1103/PhysRevLett.78.1186]

[26] Richardson KA, Imhoff TT, Grigg P, Collins JJ. Using electrical noise to enhance the ability of humans to detect subthreshold mechanical cutaneous stimuli. Chaos 1998; 8(3): 599-603. [http://dx.doi.org/10.1063/1.166341] [PMID: 12779763]

[27] Sasaki H, Sakane S, Ishida T, Todorokihara M, Kitamura T, Aoki R. Suprathreshold stochastic resonance in visual signal detection. Behav Brain Res 2008; 193(1): 152-5. b [http://dx.doi.org/10.1016/j.bbr.2008.05.003] [PMID: 18565603]

[28] Aihara T, Kitajo K, Nozaki D, Yamamoto Y. Internal noise determines external stochastic resonance in visual perception. Vision Res 2008; 48(14): 1569-73.

[http://dx.doi.org/10.1016/j.visres.2008.04.022] [PMID: 18514251]

[29] Aihara T, Kitajo K, Nozaki D, Yamamoto Y. How does stochastic resonance work within the human brain?-Psychophysics of internal and external noise. Chem Phys 2010; 375: 616-24.

[http://dx.doi.org/10.1016/j.chemphys.2010.04.027]

[30] Manfredi LR, Baker AT, Elias DO, et al. The effect of surface wave propagation on neural responses to vibration in primate glabrous skin. PLoS One 2012; 7(2): e31203. [http://dx.doi.org/10.1371/journal.pone.0031203] [PMID: 22348055]

(C) 2017 Sugimoto and Sasaki.

This is an open access article distributed under the terms of the Creative Commons Attribution 4.0 International Public License (CC-BY 4.0), a copy of which is available at: (https:/creativecommons.org/licenses/by/4.0/legalcode). This license permits unrestricted use, distribution, and reproduction in any medium, provided the original author and source are credited. 